\title{
Exposure of Underground Cable Intrusion Detection System to Transient Disturbances Caused by Nearby Lightning Strikes
}

\author{
Renata Markowska \\ Faculty of Electrical Engineering, Bialystok University of Technology, \\ Wiejska St. 45d, 15-351 Bialystok, Poland \\ r.markowska@pb.edu.pl
}

\begin{abstract}
Electronic systems with extensive underground cable installations are endangered by damage or interference during lightning as a result of current and voltage surges induced in the installations. The paper presents the study on the lightning threat to the electronic intrusion detection system based on underground cable sensors during a nearby lightning strike to the pole of the lighting system installed in parallel with the sensory cables. In the extensive intrusion detection system working in a network composed of several controller-sensorterminator units, a problem arises whether the neighbouring units should or should not be connected galvanically in order the system is less vulnerable to the effects of a lightning electromagnetic pulse. The problem is complex since the threat level may depend on many factors, i.e. the point of the strike, the lightning current, soil parameters, and configurations of the affected systems. The problem has been studied using numerical simulations based on the electromagnetic field theory and method of moments. The results show that the isolated configuration, i.e. without the galvanic continuity between the units, may be better as far as relatively low soil resistivity and low steepness of the lightning current waveform are considered.
\end{abstract}

Index Terms-Cable sensor systems and applications; Lightning protection; Lightning threat; Numerical simulation; Surge current; Transient potential difference.

\section{INTRODUCTION}

Lightning is a serious source of damage or interference in the operation of various electrical and electronic equipment and systems. The systems containing extensive cable installations located outside building structures are particularly endangered. Such systems are exposed to direct lightning strikes and a total lightning electromagnetic field. Because of conductive induction and radiation couplings with a lightning channel, current and voltage surges may arise in the installation and reach the system components.

Adequate protection of such systems against the effects of a lightning electromagnetic pulse [1], requires detailed knowledge of the threat levels and accurate tools to assess these threats. The problems are being studied widely for electrical power and telecommunication systems, both

Manuscript received 16 December, 2019; accepted 4 May, 2020

The research was conducted at BUT and financed within the research subsidy 2020 of the Institute of Automation, Electronics and Electrical Engineering provided by Polish Ministry of Science and Higher Education. overhead [2]-[5] and buried [5]-[10], regarding direct [3], [5]-[7], [10] and nearby [2], [4], [8], [9] lightning strikes. However, there is no sufficient knowledge of the lightning threat in other dedicated extensive electronic systems.

Various methods are used to assess the threats caused by lightning. For simple structures, analytical formulas or seminumerical methods are usually applied. This allows to easily assessing the effects of the nearby or direct lightning strikes [2], [4], [11]. In the case of extensive complex structures, numerical methods based on the circuit theory are more effective. These methods are usually applied to study the effects of the direct lightning strikes [3], [5], [6]. The analysis of the indirect effects of nearby lightning strikes is difficult due to the complexity of modelling various electromagnetic couplings. However, hybrid approaches are also used [12]. For complex structures, the numerical methods based on the classic electromagnetic field theory or hybrid approaches [7]-[9], [13], [14] are the most universal. They are particularly useful for studying induction and radiation coupling effects of the nearby lightning strikes. The possibilities are limited only by hardware resources.

The paper deals with the assessment of the lightning threat to an electronic intrusion detection system based on underground cable sensors made of coaxial cables of several hundred meters in length. Due to economic reasons and relatively lower exposure to direct strikes in comparison to overhead installations, such systems are often left unprotected. Nevertheless, voltage and current surges induced in long wires may cause damage to the system or serious operating problems of the attached electronic devices. The knowledge of the lightning threat is necessary for both the manufacturer and installer in order to design the optimal structure of such a system and protection measures.

The intrusion detection system is completely underground and supplied with buried power lines. In such a case, the probability of a direct lightning strike is relatively low. It is more likely that there will be indirect effects of nearby strikes to the lighting system installed in parallel with sensory cables. This case is analysed in the paper.

A single sensor for detecting intrusion is composed of two coaxial cables, up to $400 \mathrm{~m}$ in length, called "radiating cables": a transmitter and a receiver. The cables run in parallel, $1.5 \mathrm{~m}$ apart from each other, and are connected to an electronic controller at one end. The other ends of the 
cables are terminated with passive devices. The system is buried at a depth of $23 \mathrm{~cm}-40 \mathrm{~cm}$ [15].

A single controller can support two cable sensors (i.e., two pairs of the coaxial cables), which allows to increase the detection area up to $800 \mathrm{~m}$ in length or perimeter. Further increase of the detection area is obtained by creating a network composed of many controllers each supporting two cable sensors. The network can be arranged in a form of an open line (providing the border from certain directions only) or of a closed loop (the border from all directions). It is required that each controller is grounded locally, with the grounding resistance not exceeding $10 \Omega$.

The detection network, irrespective of being arranged in the open line or closed loop, can work either with or without galvanic continuity between the cable terminators belonging to the neighbouring controllers. The configuration with the metallic continuity allows limiting the number of power supply lines by connecting them to only one or a few selected controllers and supplying the other controllers via sensory cables. In the configuration without the metallic continuity, the power supply through sensory cables is not possible. Hence, the controllers have to be supplied by separate power lines.

The two configurations may result in a different response to a lightning electromagnetic pulse. In the configuration with the metallic continuity, the threat is typically related to surge currents flowing through the outer conductors of the coaxial sensory cables, whereas in the configuration without metallic continuity - to transient potential differences between the isolated terminators and sensory cables running close to one another. The two configurations may differ also by the potential differences between the metallic enclosures of the controllers or terminators located at the opposite ends of the sensory cables. The aim of this study is to compare the two configurations with respect to the threat levels that may lead to electrical breakdown of the insulation of terminators, sensory cables, and controllers' interfaces.

The problem is of a very complex nature since all the electromagnetic couplings may be significant and the threat level depends on many factors, mainly the point of a strike, the lightning current, soil parameters, and configurations of the affected systems, including grounding.

The research has been carried out with using numerical simulations based on the electromagnetic field theory and method of moments. It concerns only some of the above mentioned factors and only partly complements the study on the effects of direct lightning strikes shown in [16]-[18].

The case under study is also too complex to be fully verifiable experimentally as a whole. In practice, only some selected aspects can be verified [19], and this will be done in further research. However, some comparisons of current distributions and potentials for a simple intrusion detection arrangement computed with the used simulation method and analytical formulas are shown in [18].

\section{DEVELOPMENTS OF THE CASE UNDER STUdY}

For simplicity, the case under study is composed of two controllers each supporting two cable sensors. The analysed configurations with and without the galvanic continuity between the neighbouring components are shown in Fig. 1. In the case of isolated components, the sensory cables overlap over some area (Fig. 1(b)).

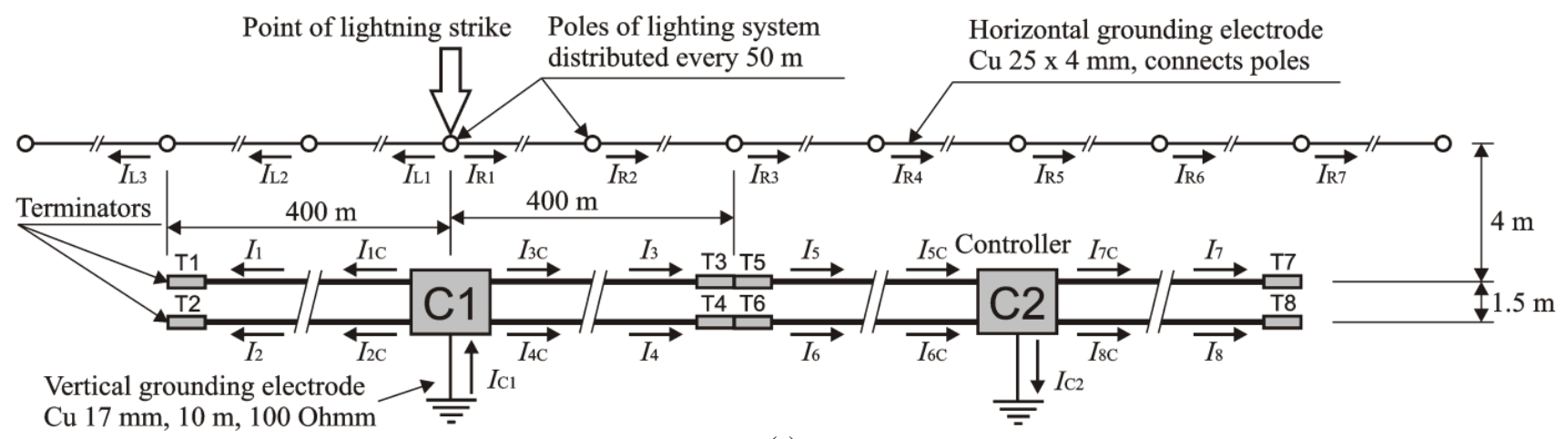

(a)

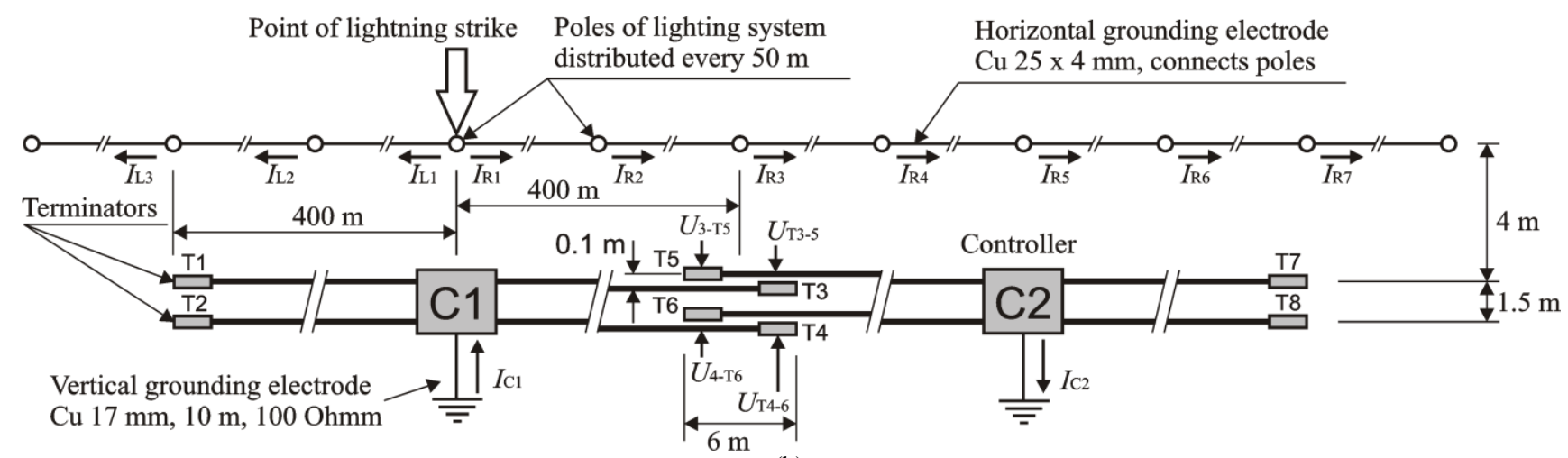

(b)

Fig. 1. Case under study in two configurations: (a) with the galvanic continuity between the neighbouring controllers; (b) without the galvanic continuity between the neighbouring controllers.

The transition zone created by the cable sensors usually requires lighting. The lighting system is installed close in parallel to the sensory cables (Fig. 1). Hence, the intrusion detection system can be affected by nearby lightning strikes 
to lighting poles. It is assumed that the lightning strikes the air termination on the lighting pole nearest to the Controller $\mathrm{C} 1$ of the intrusion detection system (see Fig. 1). The lightning current is then dissipated by the horizontal grounding system buried along and linking together the lighting poles.

The surge currents flowing in outer conductors of the coaxial sensory cables (Fig. 1(a)) and the transient potential differences between the isolated terminators and sensory cables, at the area of their nearest vicinity (Fig. 1(b)), have been adopted as measures of threat for the configurations with and without the galvanic continuity, respectively.

Moreover, the transient potential differences between the metallic enclosures of the controllers or terminators located at the opposite ends of the sensory cables have been computed. The potential difference influences the surge voltage between the inner and outer conductors of the coaxial sensory cable at the device's interface, which may lead to the breakdown of the interface.

It should be pointed out here, that due to travelling wave phenomena, the potential difference is not in any case equal to the voltage at the device's interface. It is understood here only as a relative measure, just to compare the results for two configurations, since the simulation tool does not allow to include the inner conductors of the coaxial cables.

The lightning strike was represented by an ideal current source located at the point of the strike (Fig. 1). The lightning current wave was described by the following formula [1]

$$
i(t)=\frac{I}{\eta} \times \frac{\left(t / \tau_{1}\right)^{10}}{1+\left(t / \tau_{1}\right)^{10}} \times e^{-\frac{t}{\tau_{2}}},
$$

where $I=100 \mathrm{kA}$ is a peak value of the current wave, $\eta=$ 0.93 is a correction factor, $\tau_{1}=19 \mu \mathrm{s}$ is a front time constant, and $\tau_{2}=485 \mu$ s is a tail time constant.

The parameters in (1) were set as required by standard [1] in order to obtain the short duration impulse current wave of $10 / 350 \mu$ s with the $100 \mathrm{kA}$ peak value.

\section{The Numerical Simulation Method AND ASSUMPTIONS}

Numerical simulations have been carried out using a specialized software package, namely, CDEGS [20]-[23]. The computations of the electromagnetic quantities in frequency domain have been done with HIFREQ [20]. Fast Fourier Transformations between time and frequency domains have been performed using FFTSES [22].

The computation methodology implemented in HIFREQ is based on the electromagnetic field theory. Two-potential electric field integral equations are formulated based on Maxwell's equations and are solved numerically with using the method of moments and the thin-wire approximation. The equations are formulated for a user-defined threedimensional network of interconnected or isolated thin, cylindrical conductors composed of shorter segments. The network is located in a multi-layered medium (air and a few layers of soil). The user [20] defines electrical parameters of the network and the medium.

In the numerical code, a linear current distribution along a segment is assumed, so that the segments have to be short enough to ensure good sinusoidal approximation for the current distribution. This is obtained if the segments are at least a few times shorter than the wavelength associated with the highest analysed frequency [20]. For calculating unknown current distributions in the segments, linear equations are formulated [20], [21] based on:

- Boundary conditions on the surface of the segments using the two-potential moment method;

- Kirchhoff's laws for conservation of currents at nodes and energization conditions;

- Faraday's laws for currents circulating in closed loops.

After the currents are determined, all the remaining electromagnetic quantities are calculated using the Maxwell's equations and the superposition rule.

In the HIFREQ environment, the configurations from Fig. 1 have been represented with networks composed of thin, cylindrical segments made of copper. The conductors of a cross-section other than circular have been represented by their circular equivalents of the same perimeter. The segmentation has been done, so that the segment lengths not to exceed $0.7 \mathrm{~m}$. Uniform soil was assumed with resistivity of $100 \Omega \mathrm{m}$ and relative permittivity equal to 10 .

The parameters of the thin-wire representations of the analysed configurations (Fig. 1) are presented in Table I.

TABLE I. PARAMETERS OF THE THIN-WIRE REPRESENTATIONS OF THE STUDIED CONFIGURATIONS (FIG. 1).

\begin{tabular}{|c|c|c|c|}
\hline Parameter & Unit & Value & Remarks \\
\hline \multicolumn{4}{|c|}{ Outer conductor of the coaxial sensor cable } \\
\hline Inner radius & $\mathrm{mm}$ & 6.2 & \multirow{2}{*}[24]{} \\
\hline Outer radius & $\mathrm{mm}$ & 6.53 & \multirow{2}{*}[15]{} \\
\hline Base length & $\mathrm{m}$ & 400 & \multirow{2}{*}{ Based on [15] } \\
\hline Outer metallic enclosure of the terminator \\
\hline Inner radius & $\mathrm{mm}$ & 14 & \\
\hline Outer radius & $\mathrm{mm}$ & 15.25 & \\
\hline Length & $\mathrm{mm}$ & 121 & \\
\hline External insulation on the sensor cable and terminator \\
\hline Thickness & $\mathrm{mm}$ & 2 & \\
\hline Relative permittivity & - & 1 & \\
\hline Resistivity & $\Omega \mathrm{m}$ & $10^{9}$ & \multirow{2}{*}{ Max. allowable } \\
\hline Vertical grounding electrode of the controller \\
\hline Diameter & $\mathrm{mm}$ & 17 & \\
\hline Length & $\mathrm{m}$ & 10 & \\
\hline Horizontal grounding electrode of the lighting system \\
\hline Diameter & $\mathrm{mm}$ & 37 & \\
\hline Base length (between poles) & $\mathrm{m}$ & 50 & \\
\hline \multicolumn{4}{|c|}{} \\
\hline
\end{tabular}

The electrical parameters of the insulation differ slightly from those of typical polyethylene. However, the difference will not influence the results much.

\section{Simulation Results}

The computed waveforms of lightning currents flowing along the horizontal grounding electrode of the lighting system (Figs. 1(a)-1(b)) are presented in Fig. 2.

The lightning current flowing from the struck pole into the horizontal grounding electrode divides evenly between both sides of the electrode. The current wave in the grounding electrode changes significantly as it moves away from the striking point. In particular, its front time becomes longer with the distance. It confirms that higher frequency 
components dissipate in the soil closer to the point of the strike and low frequency components propagate farther.

The currents flowing in two parts of the electrode, on the left and right from the point of the strike, are attenuated similarly up the distance of at least $200 \mathrm{~m}$. At this distance, the currents lower themselves to approximately $28 \%$. At the farther distance, the attenuation is different. At the distance of $400 \mathrm{~m}$, the currents in the left and right parts of the electrode lower themselves to approximately $5.7 \%$ and $12.4 \%$, respectively.

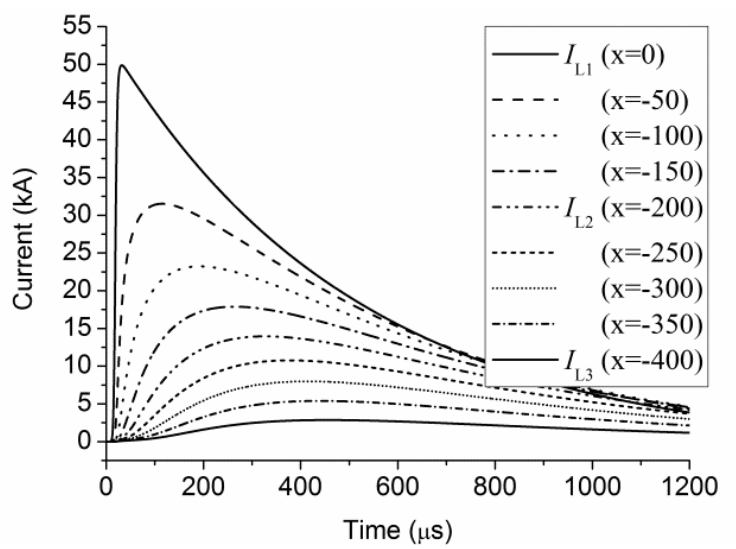

(a)

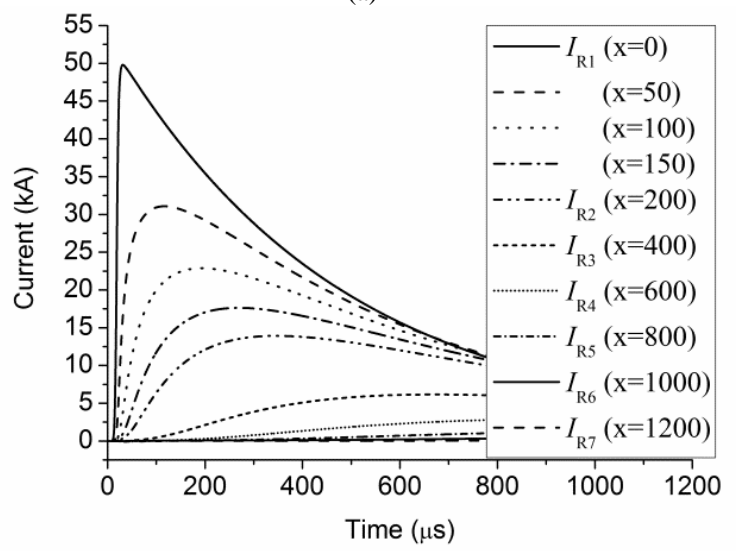

(b)

Fig. 2. Lightning currents in the horizontal grounding electrode of the lighting system on the left and right side of the struck pole (Fig. 1).

The currents induced in the vertical grounding electrodes of Controllers $\mathrm{C} 1$ and $\mathrm{C} 2$ are shown in Fig. 3.

The results reveal different behaviour of the two studied configurations in response to the same disturbance conditions. In the case of Configuration (b), only a short time current component of oscillatory type is present as the effect of induction in a single wire. In the case of Configuration (a), beside the short time current component, there is also a long duration component, which resembles the waveform of the lightning current. This long duration component is a result of transient potential distribution on the ground during dissipation of the lightning current by the horizontal grounding electrode of the lighting system. Since the vertical grounding, electrodes of Controllers $\mathrm{C} 1$ and $\mathrm{C} 2$ are at different potential, an equalizing current appears in the sensory cable linking them.

The values of the short duration component of the currents in the grounding electrode of Controller $\mathrm{C} 1$ are similar for both configurations, whereas in the case of Controller $\mathrm{C} 2$, the short duration component is significantly higher for Configuration (a) compared to Configuration (b). This may be explained partly by the fact that in Configuration (b) only the induction effect occurs, while in Configuration (a) both conductive and induction effects occur. The difference may be caused by travelling wave processes also, which are different in the two configurations due to different impedances at the end of the sensory cable path. In the case of Controller $\mathrm{C} 1$, this difference is not pronounced due to a much stronger induction effect.

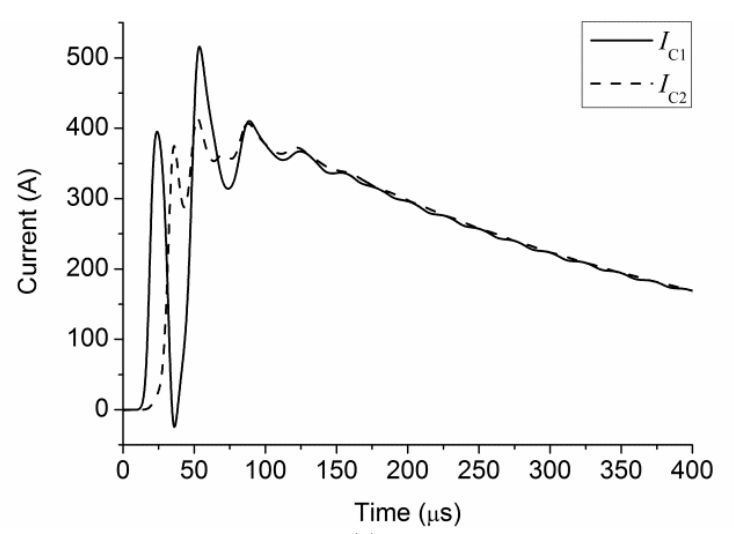

(a)

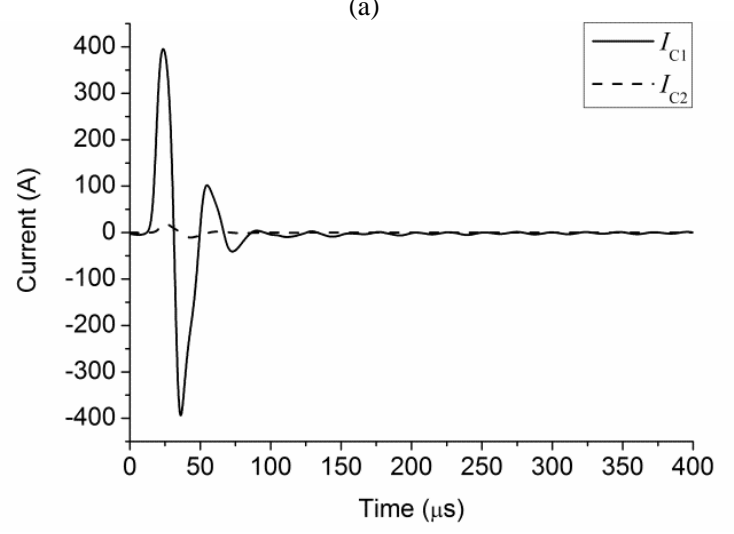

(b)

Fig. 3. Currents flowing along the vertical grounding electrodes of Controllers C1 and C2 (Fig. 1) for the analysed Configurations: (a) with the galvanic continuity between sensory cables; (b) without the galvanic continuity between sensory cables.

Some of the surge currents in the sensory cables resemble those in the vertical grounding electrodes. Examples of currents in the sensory cables are shown in Fig. 4. Based on these results, the following observations can be made:

- In Configuration (a), only the waveforms of the currents flowing through the sensory cables between Controllers $\mathrm{C} 1$ and $\mathrm{C} 2$ have a long duration component;

- The waveforms of the currents flowing through the sensory cables from Controller $\mathrm{C} 1$ to the terminators disconnected from other terminators have an oscillatory component, which is very weakly damped in time;

- The waveforms of the currents flowing through the sensory cables from Controller $\mathrm{C} 2$ to the terminators disconnected from other terminators have the oscillatory component, which is much more damped in time;

- The currents flowing through the sensory cables located close to the point of the strike are characterized by about ten times higher peak values than the currents flowing through the cables located farther.

The summary of the peak-to-peak values of the currents in the sensory cables is presented in Table II. 

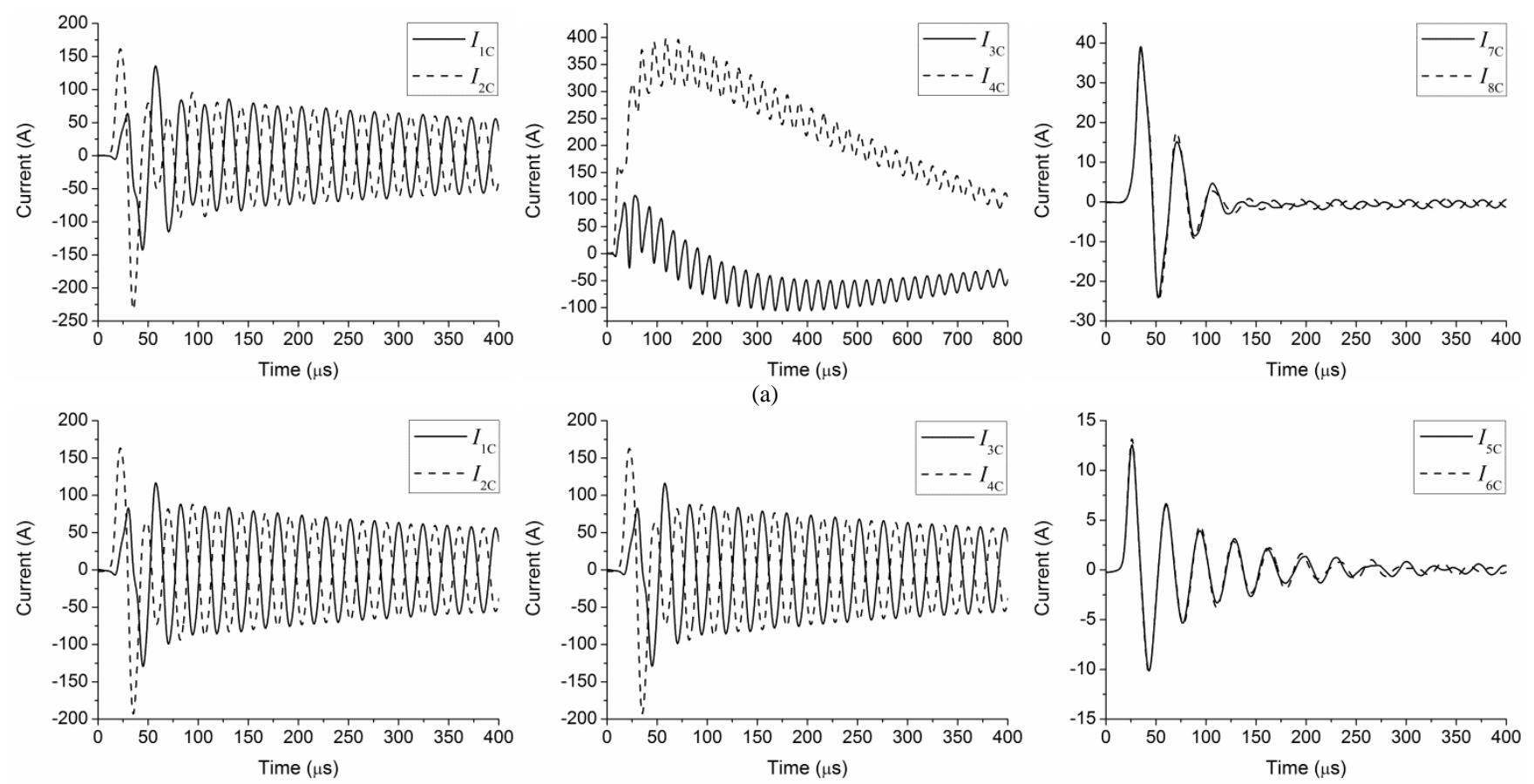

Fig. 4. Currents flowing through the sensory cables (Fig. 1) for the Configurations: (a) with the galvanic continuity; (b) without the galvanic continuity.

TABLE II. PEAK-TO-PEAK VALUES OF THE CURRENTS FLOWING THROUGH THE SENSORY CABLES (FIG. 1).

\begin{tabular}{|c|c|c|}
\hline Current (Fig. 1) & Configuration (a) & Configuration (b) \\
\hline$I_{1}(\mathrm{~A})$ & 0.34 & 0.29 \\
\hline$I_{2}(\mathrm{~A})$ & 0.57 & 0.55 \\
\hline$I_{1 \mathrm{C}}(\mathrm{A})$ & 278 & 245 \\
\hline$I_{2 \mathrm{C}}(\mathrm{A})$ & 394 & 356 \\
\hline$I_{3 \mathrm{C}}(\mathrm{A})$ & 213 & 245 \\
\hline$I_{4 \mathrm{C}}(\mathrm{A})$ & 426 & 355 \\
\hline$I_{3}(\mathrm{~A})$ & 192 & 0.29 \\
\hline$I_{4}(\mathrm{~A})$ & 386 & 0.54 \\
\hline$I_{5}(\mathrm{~A})$ & 192 & 0.023 \\
\hline$I_{6}(\mathrm{~A})$ & 386 & 0.025 \\
\hline$I_{5 \mathrm{C}}(\mathrm{A})$ & 216 & 22.7 \\
\hline$I_{6 \mathrm{C}}(\mathrm{A})$ & 427 & 23.4 \\
\hline$I_{7 \mathrm{C}}(\mathrm{A})$ & 63 & 10.53 \\
\hline$I_{8 \mathrm{C}}(\mathrm{A})$ & 63 & 10.61 \\
\hline$I_{7}(\mathrm{~A})$ & 0.08 & 0.0104 \\
\hline$I_{8}(\mathrm{~A})$ & 0.081 & 0.0106 \\
\hline
\end{tabular}

The highest currents have been obtained near Controller C1. At this area, the peak-to-peak values of currents are up to $430 \mathrm{~A}$ and $360 \mathrm{~A}$ for Configurations (a) and (b), respectively. In Configuration (a), the currents of the highest values occur along the whole path of the connected sensory cables between the controllers. For a given configuration, the currents of the highest values, which flow through the sensory cable system, are similar to the current flowing in the vertical earth electrode located nearest to the point of the strike taking into account both the waveform and the peak value (Fig. 3). Hence, the current in the vertical grounding electrode of the controller located nearest to the point of the strike gives the complete and rational information on the threat of the surge currents to the whole system.

The flow of the surge current through a conductor might cause thermal or electromechanical effects. In the case of Configuration (b), such effects may be regarded as negligible due to a relatively low peak value and short duration of the current wave, i.e. approximately $400 \mathrm{~A}$ and $50 \mu \mathrm{s}$ (Fig. 3(b)). For Configuration (a), the current of a similar peak value is observed, i.e. approximately $500 \mathrm{~A}$ (Fig. 3(a)), but the current wave lasts much longer, i.e. hundreds of microseconds resembling the original lightning current wave of $10 / 350 \mu \mathrm{s}$.

According to [1], the temperature rise of the conductor due to the surge current flow may be estimated based on specific energy contained in this current. Taking the surge current of the highest peak value and longest wave as for Configuration (a), i.e. $10 / 350 \mu \mathrm{s}, 0.5 \mathrm{kA}$, and the parameters of the sensory cable (Table I), the temperature rise will not exceed $0.7^{\circ}$. Also, according to [1], the electrodynamic forces acting on two $800 \mathrm{~m}$ long cables running in parallel $1.5 \mathrm{~m}$ apart from each other, will not exceed $14 \mathrm{~N}$. Hence, no serious thermal and electromechanical effects will exist.

The computed transient potential differences between the controllers and the terminators (Fig. 1) are shown in Fig. 5.

For both configurations, the potential differences between Controller $\mathrm{C} 1$ and terminators are close to the potential of Controller $\mathrm{C} 1$ with respect to the remote ground with the peak value of approximately $80 \mathrm{kV}$ (not shown here). The potential differences between Controller $\mathrm{C} 2$ and terminators in Configuration (a) contain more high frequency components, whereas in Configuration (b) low frequency components are more pronounced (note a different time base). Significant dependency of the potential differences on the distance from the point of the lightning strike is also observed.

Figure 6 presents the transient potential differences between the isolated terminators and sensory cables running nearby for Configuration (b), i.e. the voltages $U_{3-\mathrm{T} 5}$ and $U_{4-\mathrm{T} 6}$ indicated in Fig. 1(b). The voltages $U_{\mathrm{T} 3-5}$ and $U_{\mathrm{T} 4-6}$ are nearly the same as $U_{3-\mathrm{T} 5}$ and $U_{4-\mathrm{T} 6}$, respectively. 

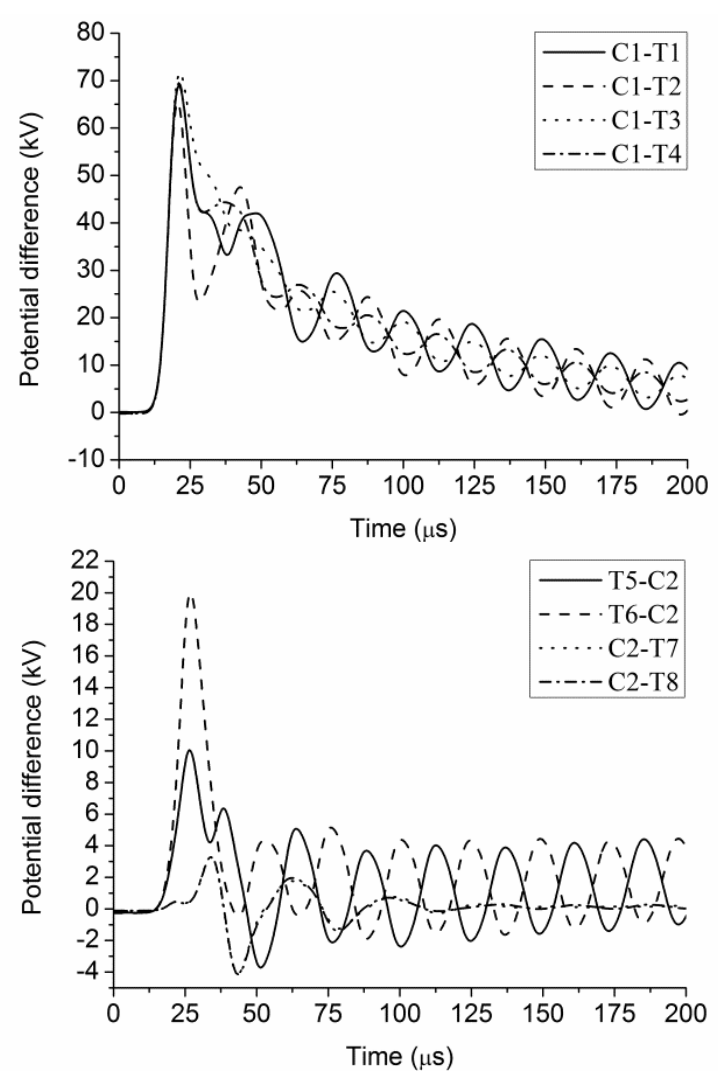

(a)
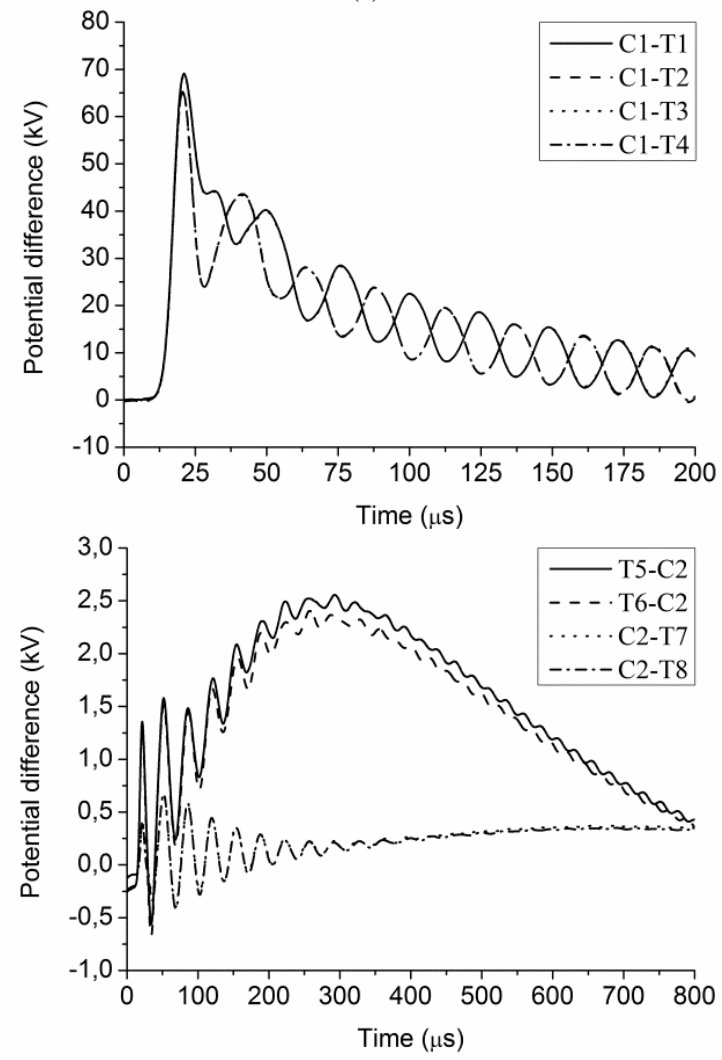

(b)

Fig. 5. Potential differences between the controllers and the terminators (Fig. 1) for the Configurations: (a) with the galvanic continuity; (b) without the galvanic continuity.

The electrical withstand of the polyethylene insulation of the thickness typical to a sensory cable [24] may be estimated to approximately $100 \mathrm{kV}$. Hence, the potential difference of $40 \mathrm{kV}$ (Fig. 6) or even $70 \mathrm{kV}-80 \mathrm{kV}$ (Fig. 5) will not pose a serious threat of the breakdown of the insulation of the sensory cable.

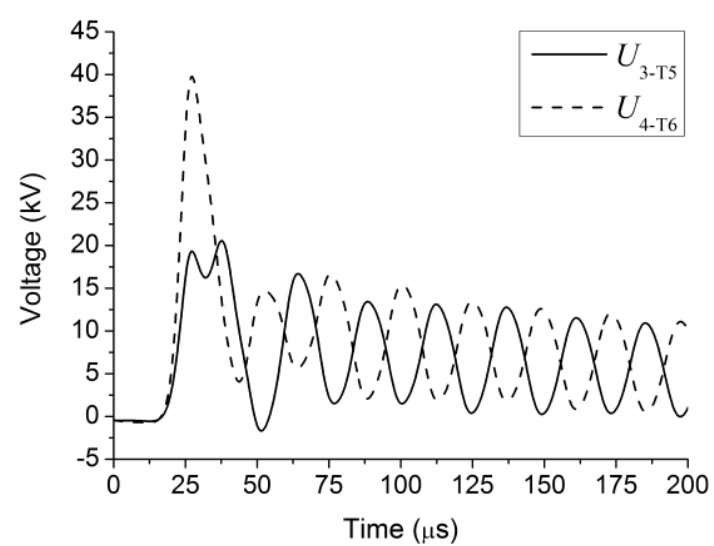

Fig. 6. Voltages between the terminators and the nearest points at the sensory cables (Fig. 1(b)) for Configuration (b) without the galvanic continuity.

The problem of electrical breakdown to the interface of the device is a result of surge voltage appearing between the inner and outer conductors of the sensory cable. The immunity to surge voltage (the wave of $1.2 / 50 \mu$ s) of signal interfaces of electronic devices is a few kilovolts, typically $1.5 \mathrm{kV}$.

The surge voltage between the inner and outer conductors of the sensory cable at the controller's interface will be dependent on the potential difference between the controllers and terminators. For both configurations, the potential differences between the devices located nearest to the point of the strike (Controller $\mathrm{C} 1$ and terminators) are characterized by the waveform of approximately 10/50 $\mu \mathrm{s}$ and the peak value of approximately $70 \mathrm{kV}$ (Fig. 5), which is over 46 times higher than the interface withstand voltage. Only the potential differences between the devices located farther from the point of the strike (Controller C2 and terminators) are dependent on the configuration (Fig. 5).

As it was mentioned in Section II, the potential difference between the controllers and terminators is not equal to the surge voltage at the controller interface, so it might only be used for relative comparisons.

The peak value of the surge voltage between the inner and outer conductor of the coaxial sensory cable may be estimated using the following approximate formula [19]

$$
U=Z_{T} \times \frac{I_{S}}{2} \times l,
$$

where $I_{S}$ is a peak value of the current flowing into the cable's outer conductor, $Z_{T}$ is a transfer impedance between the outer and inner conductor, and $l$ is a cable length.

For Configuration (a), the surge current of the highest peak value of approximately 430 A flows into the sensory cable from Controller $\mathrm{C} 1$ and keeps nearly the same value along the whole cable path until Controller C2 (Table II). Taking $I_{\mathrm{S}}=430 \mathrm{~A}, l=800 \mathrm{~m}$, and the typical value of the transfer impedance for coaxial cables with braided outer conductor $Z_{\mathrm{T}}=20 \mathrm{~m} \Omega / \mathrm{m}$ [19], the surge voltage is $3.4 \mathrm{kV}$. Such a value exceeds the typical withstand level of interfaces.

For Configuration (b), the surge current of the highest peak value of approximately $360 \mathrm{~A}$, which flows into the sensory cable from Controller $\mathrm{C} 1$, strongly diminishes while propagating along the cable path, so that it becomes 
negligible before reaching Terminators T3/T4 (Table II). Taking $I_{\mathrm{S}}=60 \mathrm{~A}, l=400 \mathrm{~m}$, and the same transfer impedance, the surge voltage is $1.4 \mathrm{kV}$, which is below the withstand level.

\section{CONCLUSIONS}

The paper presents the study on the lightning threat to the electronic intrusion detection system based on underground cable sensors built of the coaxial cables. The threat is related to the nearby lightning strike to the pole of the lighting system installed in parallel with the sensory cables. In the extensive intrusion detection system working in a network composed of several controller-sensor-terminator units, a problem arises, whether the neighbouring units should or should not be connected galvanically in order the system is less vulnerable to the effects of the lightning electromagnetic pulse. The problem is complex. It has been studied with numerical simulations based on the electromagnetic field theory.

The results show that there is no danger of either thermal or electromechanical effects caused by the surge currents in either configuration. The peak values of the currents do not exceed $430 \mathrm{~A}$ and $360 \mathrm{~A}$ for the configurations with and without the galvanic continuity, respectively.

There is also no serious threat of the electrical breakdown of the insulation between the terminators and sensory cables running nearby $(40 \mathrm{kV})$, as well as of the insulation of cables running close to the point of the strike (potential of the grounding electrode of approximately $80 \mathrm{kV}$ ). The obtained values are below the expected value of the electrical breakdown for the polyethylene insulation.

The threat of the breakdown of the controller's interface measured by the surge voltage between the inner and outer conductors of the sensory cable, has been assessed on the basis of the typical transfer impedance and the current flowing in the outer conductor. The calculated surge voltages are $3.4 \mathrm{kV}$ for the configuration with the galvanic continuity and $1.4 \mathrm{kV}$ for the isolated one. Hence, the isolated configuration seems better.

However, it should be kept in mind that the obtained results are valid only for a specific situation, particularly related to the point of the strike, the waveform of the lightning current, and soil resistivity. Higher threat levels might occur for higher soil resistivity and higher steepness of the lightning current waveform. These factors are the subject for further research.

\section{CONFLICTS OF INTEREST}

The author declares that she has no conflicts of interest.

\section{REFERENCES}

[1] Protection against lightning, Part 1: General principles; Part 2: Risk management; Part 3: Physical damage to structures and life hazard; Part 4: Electrical and electronic systems within structures., IEC Standard 62305.

[2] J. O. S. Paulino and C. F. Barbosa, "On lightning-induced voltages in overhead lines over high-resistivity ground", IEEE Trans. on Electromagnetic Compatibility, vol. 61, no. 5, pp. 1499-1506, Oct. 2019. DOI: 10.1109/TEMC.2018.2856751.
[3] H. Chen, Y. Zhang, Y. Du, and Q. S. Cheng, "Lightning transient analysis of telecommunication system with a tubular tower", IEEE Access, vol. 6, pp. 60088-60099, 2018. DOI: 10.1109/ACCESS.2018.2875723.

[4] A. Andreotti, D. Assante, A. Pierno, V. A. Rakov, and R. Rizzo, "A comparison between analytical solutions for lightning-induced voltage calculation", Elektronika ir Elektrotechnika, vol. 20, no. 5, pp. 21-26, 2014. DOI: 10.5755/j01.eee.20.5.2967.

[5] M. Hashmi, M. Lehtonen, and S. Hanninen, "Modelling and analysis of lightning overvoltage protection of MV cable laterals connected with overhead lines", Elektronika ir Elektrotechnika, vol. 123, no. 7, pp. 49-52, 2012. DOI: 10.5755/j01.eee.123.7.1325.

[6] S. Sekioka, H. Otoguro, and T. Funabashi, "A study on overvoltages in windfarm caused by direct lightning stroke", IEEE Trans. on Power Delivery, vol. 34, no. 2, pp. 671-679, Apr. 2019. DOI: 10.1109/TPWRD.2018.2883910.

[7] H. Tanaka, Y. Baba, C. F. Barbosa, T. Tsuboi, and S. Okabe, "Protective effect of shield wires against direct lightning flashes to buried cables", IEEE Trans. on Power Delivery, vol. 33, no. 4, pp. 1628-1635, Aug. 2018. DOI: 10.1109/TPWRD.2017.2746100.

[8] J. O. S. Paulino, C. F. Barbosa, and W. C. Boaventura, "Lightninginduced current in a cable buried in the first layer of a two-layer ground", IEEE Trans. on Electromagnetic Compatibility, vol. 56, no. 4, pp. 956-963, Aug. 2014. DOI: 10.1109/TEMC.2013.2292557.

[9] L. Diaz, C. Miry, P. Baraton, C. Guiffaut, and A. Reineix, "Lightning transient voltages in cables of a large industrial site using FDTD thin wire model", Electr. Power Syst. Res., vol. 153, pp. 94-103, Dec. 2017. DOI: 10.1016/j.epsr.2016.09.027.

[10] C. F. Barbosa, A. Zeddam, P. Day, and Y. Bourgeois, "Effect of guard wire in protection a telecommunication buried cables struck by rocket-triggered lightning", in Proc. of 29th International Conference on Lightning Protection, Uppsala, Sweden, 2008, pp. 6b-1-1-6b-1-6.

[11] E. F. Vance, Coupling to shielded cables. Wiley, Interscience, 1978.

[12] R. Ziemba, G. Masłowski, and T. Kossowski, "Analysis of the overvoltages caused by nearby lightning stroke", in Proc. of 24th International Conference on Electromagnetic Disturbances EMD'2017, Bialystok, Poland, 2017, pp. 147-150.

[13] R. Alipio and R. Segantini, "Electromagnetic disturbances propagation along a grounding grid subjected to lightning currents", Przegląd Elektrotechniczny, R. 94, no. 2/2018, pp. 5-8, Feb. 2018. DOI: 10.15199/48.2018.02.02.

[14] R. Alipio and A. De Miranda, "Influence of frequency-dependent characteristics of grounding and line models on transient overvoltages in overhead lines", Przeglad Elektrotechniczny, R. 94, no. 2/2018, pp. 1-4, Feb. 2018. DOI: 10.15199/48.2018.02.01.

[15] Doziemny system ochrony obwodowej HF400R, Catalog card (in Polish), STEKOP S. A. [Online]. Available: www.stekop.pl

[16] K. Aniserowicz and R. Markowska, "Semi-analytic calculations of overvoltages caused by direct lightning strike in buried coaxial cable", Przegląd Elektrotechniczny, R. 93, no. 12/2017, pp. 1-5, Dec. 2017. DOI: $10.15199 / 48.2017 .12 .01$.

[17] R. Markowska and K. Aniserowicz, "Lightning currents and overvoltages in underground radiating cables of intrusion detection system", Przeglad Elektrotechniczny, R. 94, no. 2/2018, pp. 34-40, Feb. 2018. DOI: 10.15199/48.2018.02.09.

[18] K. Aniserowicz and R. Markowska, "Analytical and numerical calculations of overvoltages in underground cable intrusion detection system directly hit by lightning", in Proc. of 34th International Conference on Lightning Protection: ICLP 2018, Rzeszow, Poland, 2018. DOI: 10.1109/ICLP.2018.8503285.

[19] R. Markowska and A. W. Sowa, Ochrona Odgromowa Obiektów Telekomunikacyjnych (in Polish). Bialystok University of Technology, OWPB, Białystok, 2013.

[20] HIFREQ User's manual, Safe Engineering Services \& Technologies Ltd., Montreal, Canada, 2000.

[21] Computation of electromagnetic fields created by rectilinear current sources in a stratified medium, Safe Engineering Services \& Technologies Ltd., unpublished.

[22] FFTSES user's manual, Safe Engineering Services \& Technologies Ltd., Montreal, Canada, 2000.

[23] CDEGS Current Distribution, Electromagnetic Fields, Grounding and Soil Structure Analysis, Safe Engineering Services \& Technologies Ltd., Montreal, Canada, 2000.

[24] Technical data sheet - Radiating cables, Kabelwerk, EUPEN AG, Rev.: 08/2010-10-07. 